\title{
Commentary \\ The Origin of the Constant Carbohydrate Diet
}

\author{
Charles Herbert Read Jr. \\ Department of Pediatrics, The Roy J. and Lucille A. Carver College of Medicine, University of Iowa Health Care, \\ 200 Hawkins Drive, Iowa City, IA 52242-1009, USA
}

Correspondence should be addressed to Charles Herbert Read Jr., charlesread@msn.com

Received 7 December 2008; Accepted 22 December 2008

The Constant Carbohydrate diet, based entirely on carbohydrate exchanges, is now widely used in the dietary treatment of diabetes mellitus. Being based on sound scientific principles and simple in design, the Constant Carabohydrate diet is appropriate for all those having diabetes mellitus, young or old, no matter their ethncity. This report describes why and how it was developed in 1951. Its simplicity makes it adaptable to all ethnic diets.

Copyright () 2009 Charles Herbert Read Jr.. This is an open access article distributed under the Creative Commons Attribution License, which permits unrestricted use, distribution, and reproduction in any medium, provided the original work is properly cited.

Within an hour of reporting to the Winnipeg Children's Hospital as the newly appointed Assistant Professor of Pediatrics at the University of Manitoba College of Medicine in September, 1951, I was asked to assume responsibility for the diabetes service. I was totally surprised. Obviously they had not understood my postgraduate activities.

After graduating from McGill Medical School, I was in the Royal Canadian Navy for three years and returned to a pediatric residency at the Montreal Children's Hospital $(\mathrm{MCH})$ in 1946 . During a rotation to the Royal Victoria Montreal Maternity Hospital, I became intrigued by the clinical problems that a newborn infant of a diabetic mother had. I reviewed the world's literature and found they were not even described. This led me to spending the next four years as a Fellow, two at McGill (Montreal Children's Hospital), and two at Harvard (Massachusetts General Hospital), virtually all in laboratory-based research $[1,2]$. In this interval, not only was I never involved in the treatment of anyone who had diabetes, but also I did not even see a child who had it. However, I did learn the pathophysiology of diabetes and thoroughly understood Butler's method [3] for treating diabetic ketoacidosis.

I quickly thought the offer over and decided that by working with the children and their parents I probably could learn the day to day problems that face children with insulindependent diabetes and how to cope with them. If I needed help, I certainly would ask for it, but in the past four years, I had a lot experience solving problems. So without revealing my deficiencies or my considerable anxiety, I accepted the responsibility.
In the clinic, the patients and their mothers told me their major problems were with the American Dietetic, American Diabetic (ADA) diet. "Nothing seemed to work." I listened carefully to their descriptions of trying to make the triple exchanges. Even weighing portions was unsuccessful.

This prestigious ADA exchange diet was taught in virtually all the diabetic centers in Canada and the United States. Its concept was that any food which contains an equivalent amount (within 3 grams) of carbohydrate, fat, and protein could be substituted for a similar food if they were in the same food group. The groups were Milk, Meat (sometimes divided into high- or low-fat subgroups), Vegetables, Breads, and Fats. For example, if an eight-ounce glass of skim milk was substituted for an eight-ounce glass of whole milk containing 10 grams of fat, where would one find the 2 fat exchanges that were needed. The implication was that the insulin need was related to the total calories ingested.

It made little sense to me that while insulin is necessary to produce fat, it has a negligible role in its catabolism. So why to pay attention to fat in so far as the insulin requirement is concerned?

Fifty five percent of amino acids are gluconeogenic and require insulin for their metabolism, so the 12 -to- $20 \%$ dietary protein needed to supply $0.6 \mathrm{gm}$ per kilo of body weight, then generally considered desirable, would use 6 to $10 \%$ of the daily insulin requirement. When I examined the dietary records of these patients, I found that their protein intakes from day to day were remarkably similar, so I decided the dietary protein and, therefore, its insulin need could be considered constants. 
I concluded that because insulin is required for the metabolism of the dietary carbohydrate, an appropriate diet for diabetes is one in which the carbohydrate content of each of the meals, although different in amounts at breakfast, lunch, and dinner, would be the same from day to day. Variations in the protein and fat content are ignored.

As the dietitian at the Winnipeg Children's Hospital, Ms. Marion Adams, as well as all other dietitians of the era had been indoctrinated in the ADA diet, I realized that I would have to convince her that the new diet was fundamentally sound. I reminded her that fat does not require insulin, that protein can be considered a constant, and that the major food requiring insulin was carbohydrate. By using a meal pattern based on the individual's own choice, this new diet would allow the individual to consume carbohydrates, proteins, and fats at each meal as desired. Only the carbohydrate is counted, so any food may be included in the diet by referencing a Carbohydrate Guide and staying within 3 grams of the decided amount of carbohydrates at each eating time. This is the Constant Carbohydrate diet.

After she had used this diet for several months, Adams [4] noted that although at first the mothers were confused by this seemingly drastic change, they and the patients easily and even happily adapted to this new way of thinking and doing, especially those of different ethnic origins. Her reaction was typical of the responses of each dietitian who subsequently began using the diet.

At that time and for years later, there was a controversy about whether blood glucose control mattered. My opinion was that as the blood glucose levels in a normal person traverse a relatively narrow range, it must be physiologically important. Therefore, I concluded that the objective of a rational treatment program would be to keep the blood glucose levels as close to normal as possible. As daily decisions about insulin dosage were dependent on the grossly inadequate data derived from urinary glucose tests, as well as the limitations of the insulins available, it was at that time an objective impossible to achieve; but even if the goal was not attainable, it was still the ideal to aim.

There being no commercially "smart" insulin that could mimic the availability of insulin in the normal healthy individual, I used a combination of the available insulins to approximate this objective. Mixtures of Regular and NPH insulins seemed to work best and usually needed to be given at least twice each day. We began teaching our patients how to make these mixtures and how to adjust their insulin doses at home. My objective was to eventually make each patient essentially capable of managing their own care.

My first public presentation of this program was in 1955, the year after I joined the Pediatric Department of the University of Iowa College of Medicine. It was at an American Academy of Pediatrics Round Table, and summarized in Pediatrics [5]. The feedback was that it was too radical. A 1958 paper in the Journal of the Iowa Medical Society featured [6] insulin therapy, but emphasized that the carbohydrate content of the diet is kept constant each day. A year later, the World Health Organization's Manual of Paediatrics for South-east Asia [7] contained a chapter on diabetes mellitus in which I described the Constant Carbohydrate diet in some detail. The use of examples of foods commonly eaten in that part of the world, such as one slice of bread being equivalent to $1 / 2$ cup of mashed potatoes, $3 / 8$ cup of rice, or $1 / 2$ cup of dhal, demonstrated that this diet could be used in culturally diverse societies.

In the early 1960s, I began routinely measuring the patients' cholesterol levels. Finding them frequently elevated, I reduced the fat content of the diet to not more than $30 \%$ of the calories in 1967 .

I believe that the Constant Carbohydrate diet was the first diet for patients with diabetes mellitus that was based solely on carbohydrate exchanges. Believing that none of the scientific medical journals would be interested in publishing a paper with no controls, its further dissemination was largely by physicians and dietitians, who had trained in this hospital, as well as the ongoing publications of the Dietetic Department of the University of Iowa Hospitals and Clinics and personal presentations.

\section{References}

[1] C. H. Read, "Observations on the offspring of diabetic mothers," American Journal of Obstetrics and Gynecology, vol. 61A, pp. 392-398, 1951.

[2] C. H. Read, E. H. Venning, and M. P. Ripstein, "Adrenal cortical function in newly-born infants," The Journal of Clinical Endocrinology \& Metabolism, vol. 10, no. 8, pp. 845-857, 1950.

[3] A. M. Butler, "Diabetic coma," The New England Journal of Medicine, vol. 243, no. 17, pp. 648-659, 1950.

[4] M. Adams, personal communication, 2004.

[5] C. H. Read and P. Baer, "Diabetes in children; summary of round table discussion," Pediatrics, vol. 17, no. 4, pp. 605-611, 1956.

[6] C. H. Read, "Insulin therapy of diabetic children," Journal of the Iowa State Medical society, vol. 48, no. 4, pp. 183-186, 1958.

[7] C. H. Read, "The management of diabetes," in Manual of Paediatrics for South-East Asia, P. Robinson and A. Walgren, Eds., pp. 214-222, The World Health Organization, Longmans Green, New Delhi, India, 1959. 